\title{
Design and Implementation of Collaborative Management System for Effective Learning
}

\author{
Tochukwu A. Ikwunne ${ }^{1}$, Wilfred Adigwe ${ }^{2}$, Christopher C. Nnamene ${ }^{3}$ \\ Noah Oghenefego Ogwara ${ }^{4}$, Henry A. Okemiri ${ }^{5}$, Chinedu E. Emenike ${ }^{6}$ \\ Department of Computer Science \& Informatics, Alex Ekwueme Federal University Ndufu-Alike, Abakaliki, Nigeria ${ }^{1,3,5,6}$ \\ Department of Computer Science, Delta State University of Science and Technology, Ozoro, Nigeria ${ }^{2}$ \\ School of Engineering Computer and Mathematical Science, Auckland University of Technology, Auckland, New Zealand ${ }^{4}$
}

\begin{abstract}
Recently, the need for online collaborative learning in educational systems have increased greatly because of COVID19 pandemic. The pandemic has provided an opportunity for introducing online collaboration and learning among instructors and students in Nigeria. Currently, several schools, colleges, universities in Nigeria have discontinued face to face teaching and learning. Many schools resorted to ineffective alternatives such as the use of televisions and radio programmes to carry out distance education (DE). These alternatives have challenges such as lack of monitoring and evaluation of students' learning. Collaborative Learning Management System (CLMS) is a research project that aims to assist instructors in achieving their pedagogical goals, organizing course content, collaborating, monitoring, and supporting students' online learning. It is an interactive, online based as well as android based system that has been designed, implemented, tested. The system demonstrates that it is robust, interactive, and achieves the predefined goals. As a Software Development Approach, it was created using the Rapid Application Development (RAD) Methodology. It also provides a secured and reliable platform for the schools, colleges, and universities to implement an online learning system.
\end{abstract}

Keywords-Collaborative learning; conventional education; effective learning; e-portfolio; interactive board

\section{INTRODUCTION}

The COVID-19 pandemic has caused significant disruption to educational activities around the world, particularly in Nigeria. Many countries resorted to online based distance education (DE) for learning continuity. However, many schools in Nigeria are applying the method of use of television and radio-based programmes, to carry out distance education. This method poses a great challenge because it's difficult to monitor and evaluate students learning. A few institutions in Nigeria are now carrying out their academic activities using one form or another of Information Communication Technology (ICT). However, for some institutions in Nigeria, the desire to engage in online learning remains a dream due to inadequate ICT infrastructure. However, the rapid development of ICTs in Nigeria presents an opportunity to consider its use in the promotion of distance education [1]. According to the authors in [2], DE is regarded as a novel method for delivering computer-mediated, well-designed, student-centered, and interactive learning environments to students at any time and from any location by utilizing the internet and digital technologies in conjunction with instructional design guidelines. It benefits students by increasing access to learning opportunities, at the right time and place, making a wide range of learning resources available, improving opportunities for personalized learning [3, 4], and ushering in more powerful cognitive tools. However, the educational sector in Nigeria continues to rely on conventional teaching methods that are incompatible with students and teachers in an age of ICT development [5].

The authors in [6] stated that the conventional education at this present time has not added educational contents to the new generation students. Conventional education has not keep-pace with modern thought and the educational sectors need, to suit with type of students in the twenty first century [6]. The Collaborative Learning Management System (CLMS) is a collaborative learning platform used to manage and integrate online learning courses between teachers and students for effective delivery of lectures through the internet. At the moment, online learning management systems (CLMS) are commonly used in educational sectors all over the world because they make it simple to create, deliver, and learn course content, as well as track and report on course and student performance [7].

The online learning system is a supplement to the conventional concept of education; the current education system is shifting from the teacher imparting knowledge to the students, to promoting the students' desire to learn. This type of transition can inspire an individual to develop a love of learning, problem solving, and comprehension, as well as a strong long-term memory. In such a learning environment, students can actively learn and acquire skills to solve a variety of problems, as well as assess and value their own works and ideas. The lecturing, listening, and note-taking processes do not entirely disappear in the CLMS, but they are supplemented by other processes based on student discussion and active work with the course material. Collaborative learning teachers see themselves as master creators of intellectual experiences for students rather than expert transmitters of information to students [8].

In view of the above discussion, this work focused on the design and implementation of CLMS to enhance, integrate an effective learning process. In general, components of the system contain interactive management features, quiz and assessment utilities and announcement medium. The assessment utilities allow instructors to systematize basic assessment tasks to the students. Assessments are delivered to

${ }^{1}$ https://blog.capterra.com/what-is-rapid-application-development/ 
the students online, and upon conclusion, grades and detailed feedbacks are delivered to the students. The system provides the following solutions: collaborative learning through interactive tools, easy knowledge management, assessments, and quiz. Chats between instructors to students and students to students. Repository of course materials via e-portfolio, Personalize learning management tools, secure and customizable learning system.

The other sections of this paper presents: (1) a literature review on the need to reconsider the design of conventional educational system to include online collaborative learning in educational systems and the importance and features of online collaborative learning management system, (2) identification of problems with the conventional system of education and presented objective of this study, (3) presentation of the system overview and architecture of a new online collaborative management system and the test results and (4) conclusion and recommendations.

\section{LITERATURE REVIEW}

The need to reconsider the design of conventional educational system to include online collaborative learning in educational systems has increased greatly because of COVID19 pandemic. The pandemic has provided an opportunity for introducing online collaboration and learning among instructors most especially in Nigeria. Many schools, colleges, and higher institutions in Nigeria have discontinued face to face teaching and learning and relied on ineffective alternatives such as the use of televisions and radio programmes to carry out distance education (DE) [8]. These alternatives have challenges such as lack of monitoring and evaluation of students' learning. As a result, an online collaborative learning management System (CLMS) is required to assist teachers in achieving their pedagogical goals, organizing course content, collaborating, monitoring, and supporting students' online learning.

The process of standardizing collaborative learning technology is taking the lead in research efforts into onlinebased education [9]. The author in [10] emphasized the importance of researchers conducting additional research on the role of collaboration in learning in order to develop deeper theoretical frameworks that can better guide the development of technology-supported learning settings.

Some trends have necessitated the use of online-based learning. Platforms for collaborative learning management systems (CLMS) have abundant resources, sharing, and convenience. All these characteristics combine to make it one of the more potent learning tools. CLMS has good functionality for assisting students' learning and encourages positive attitudes in both students and teachers [11]. On-line collaborative learning is heavily reliant on the internet and employs collaborative learning methods. The methods make full use of internet resources, promoting learners' abilities to self-learn, communicate, and direct learners' activities with others, as well as assisting in supporting learners to solve practical problems. Based on what has been discussed thus far, one can reasonably conclude that online collaboration can be delivered in the form of discussion among the entire group or students or within smaller groups of students, however, [12] emphasized that smaller groups make better learning outputs. The author in [13] posited that ccollaborative learning can help in demonstrating new knowledge.

Collaborative learning is known by a variety of names. Cooperative learning, collaborative learning, collective learning communities, peer teaching, peer learning, and team learning are some examples. All of these names have one thing in common: they all necessitate collaboration. Furthermore, research suggests that collaboration may provide more opportunities for equality in group work than conventional face-to-face group work [9], because the latter approach frequently bases group "decision-making" on students who are considered "bright" by their teachers in the class. The section that follows discusses the various types of CLMS and their features.

\section{A. Collaborative Learning Management System (CLMS) and their Features}

There are several types of CLMS available on the market [14], including commercial or proprietary, as well as free software or free courses [15]. Among the various types of CLMS types that are implemented in higher institutions are Blackboards (proprietary environment). The best CLMS for a given institution is determined by its characteristics and objectives [15]. According to [16], several researchers investigated the necessary elements for selecting a CLMS. A team from the Federal University of Rio de Janeiro (UFRJ) Technology, Education, and Society Group [17], for example, identified seven major categories of tools in an educational platform in 2004. The categories are interface, navigation, evaluation, didactic resources, communication / interaction, coordination, and administrative support.

There are classes that enable efficient Collaborative Learning Management System (CLMS). They are 1) Interface category which creates communication between users and system. 2) Navigation category that establishes easy flow between Collaborative Learning Management System (CLMS) pages. It includes evaluation forms to determine whether a student has fully grasped the material. 3) The Communication / Interaction category that depicts flow of information between learners in a Collaborative Learning Management System. 4) The Coordination category focuses on the instructors' actions of module planning, creation, execution, and control. 5) The Administrative Support category focuses on both the administration tools and environmental management [17].

In order to analyze student interaction in online-based courses, students' interactions are divided into two main categories which include content interaction and social interaction [18]. The content interaction is focuses on the module content such as the study materials, assignment and any other important information that help the effectiveness of the student study. Social Interaction aids students to learn about their peers and resist the separation and frustration of an individual student that are common problems in Web-based course. 
The presence of online CLMS to support continuing of teaching and learning will guide the implementation of education system during this challenging crisis of COVID 19 pandemic.

\section{Statement OF THE PROBLEM}

The following challenges are associated with the conventional education system and current alternative methods:

1) Learning is restricted to a specific time, this results to an inadequate attention of the student.

2) Inability for student in distance locations to participate in learning making it difficult for those that is far from the location to be involved in the learning.

3) Limited access to the learning materials to the students making it difficult for student to have access to all the study materials at a particular time.

4) Students are required to physically be present in the classroom in order to gain knowledge, sacrificing all other responsibilities.

5) Students submit assignment to the lecturer through hard copies.

6) The lack pre-existing collaborations for the design and broadcasting of the educational content via television and radio.

\section{OBJECTIVES OF THE STUDY}

The aim of this work is to develop and implement the Collaborative Learning Management System for online distance education with the specific objectives as follows:

1) To create an interactive board where student can interact and share idea with each other.

2) To integrate an e-portfolio in the system which would serves as the repository storage of learning material needed for the student.

3) To develop a web based CLMS application for student effective learning.

4) To create user interface is compatible and responsive to any device being used.

\section{SYSTEM OVERVIEW}

The design of this collaborative learning management system platform is based on the need to provide a system that would ensure that a student is fully involve in learning activities of the institution irrespective of the geographical location. The system would provide some functionality such as interactive board/chat box which would aid student to lay comment as well allows the student-student and lecturer/teachers interactions. Also, an integration of eportfolio in the system which would serves as the repository storage of learning material needed for the student. The system graphical user interface would be made to be easily accessible via web browsers and compatible and responsive in any device being used. Rapid Application Development (RAD) ${ }^{1}$ Software methodology was adopted in the design of the proposed system. The RAD methodology has the following phases:
- Requirement planning: Also known as a project scoping meeting. Although the planning phase is shorter in this methodology than in others, it is critical to the overall success of the CLMS development. The phase specifies the reporting functions and data subject areas of the CLMS, as well as the system's scope. It is also known as the concept definition stage.

- User Design: This is also referred to as functional design. Once the project has been scoped, development can begin, fleshing out the user design through multiple prototype iterations and user feedback. We worked with users to create a functional prototype of CLMS components.

- Construction: The physical CLMS is completed during the construction phase, the conversion system is built, and a user aid and implementation work plan is developed. This stage, also known as the development stage, is broken down into several smaller steps, including program development, coding, and unit, integration, and system testing.

- Cutover: This stage, also known as the implementation phase, includes final user testing, training data conversion, and application system implementation.

The high-level model of CLMS is shown in Fig. 1. It is broken down into units and subunits so that the CLMS can be easily understood starting from the subunits. Fig. 2 shows the system architecture of the new CLMS. It defines the behaviour and structure of a system.

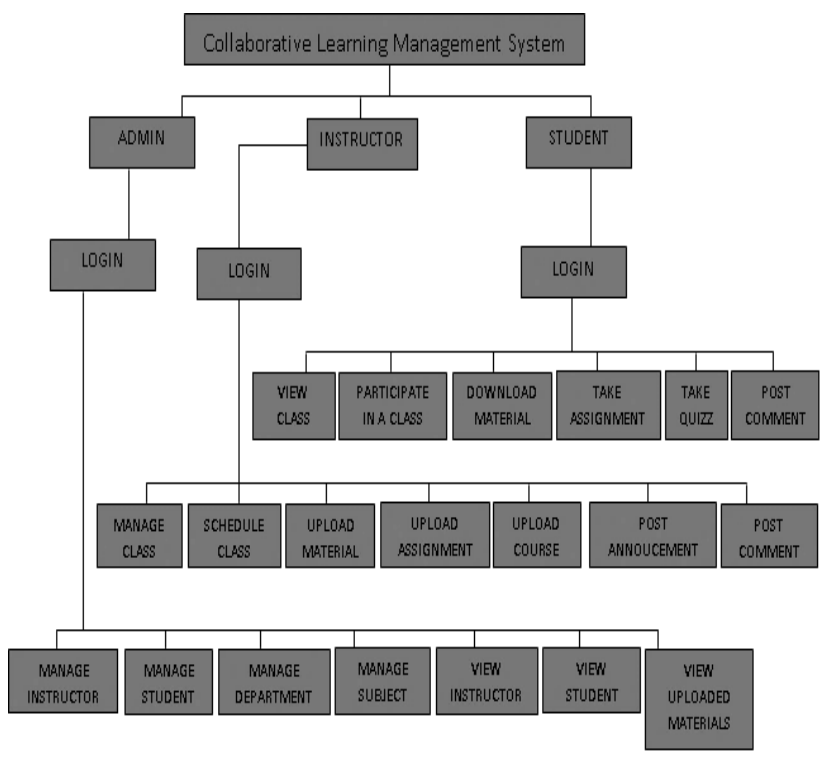

Fig. 1. High-level Model of the New CLMS.

\section{SYSTEM ARCHITECTURE}

The CLMS architecture presents a set of artifacts and their relationships, which guide the system's selection, creation, and implementation. Fig. 2 depicts the new CLMS's system architecture. These sets of artifacts depict the relationships between CLMS components and are represented in Fig. 3 by a use case diagram and Fig. 4 by an entity relationship diagram. 


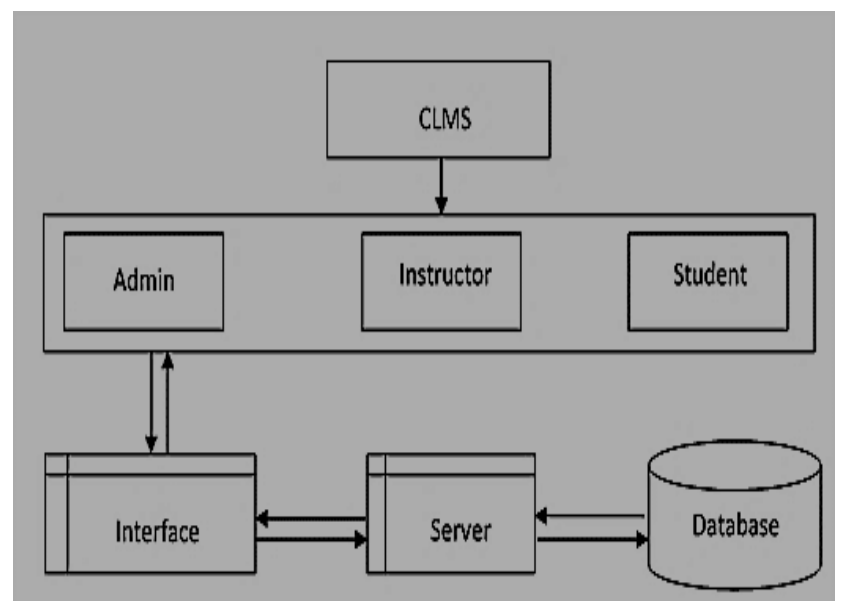

Fig. 2. System Architecture Diagram of the New CLMS.

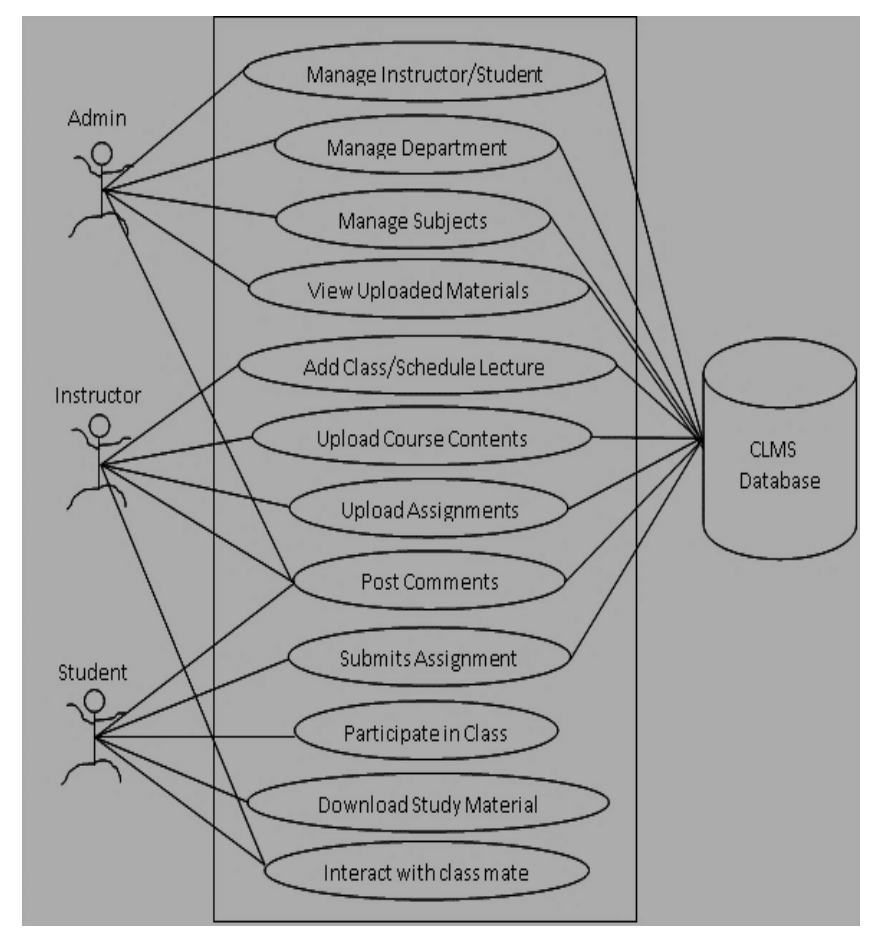

Fig. 3. The use Case Diagram of the System.

- Entity Relationship Diagram (ERD): The Entity Relationship Diagram (shown in Fig. 4) provides a clear picture of the relationships between the various entities associated with the system. It describes how one entity's flow of action is related to other system entities.

\section{A. Menu Design}

The main menu of this system is design in such a manner that it will enable the users of the system to easily navigate or taken to the submenu to carry out specified tasks. At the menu they are required to provide their login details after which access to other sub modules would be granted to them. There are three main group of users captured in this system. These are the Administrator of the system, the Instructor/teacher, and the Student. The main menu interface will allow either the admin or instructor and student to navigate to the various sections which will enable module to have their own menu that serves the main functions to enable them to effectively manage the system. The diagram in Fig. 5 shows the main menu for instructors and student log in. Fig. 6 displays the main menu design for Admin.

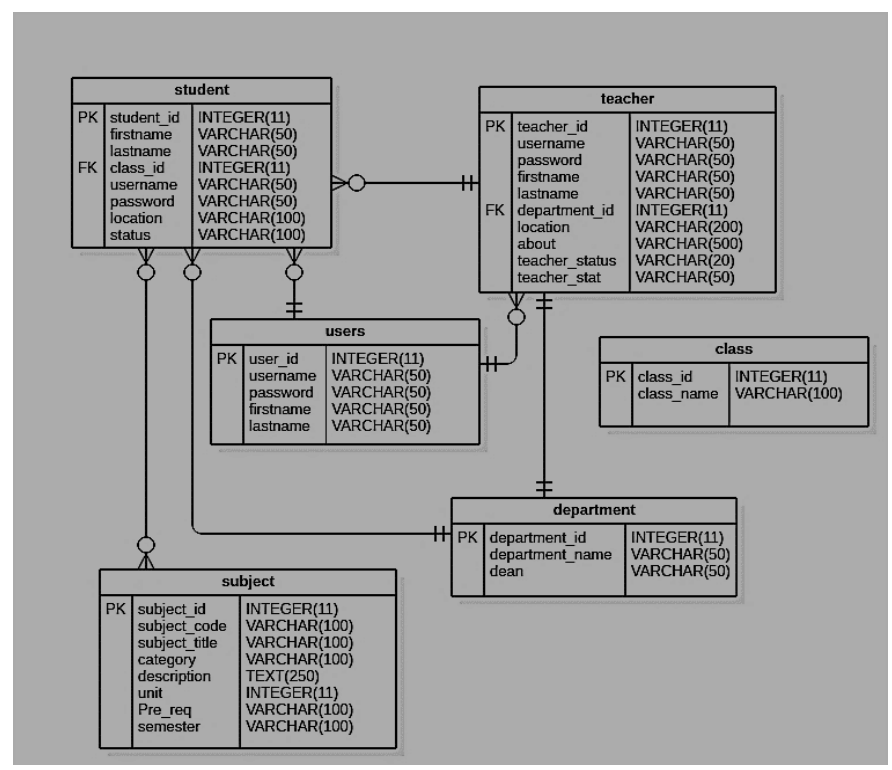

Fig. 4. Entity Relationship Diagram (ERD) of the New System.

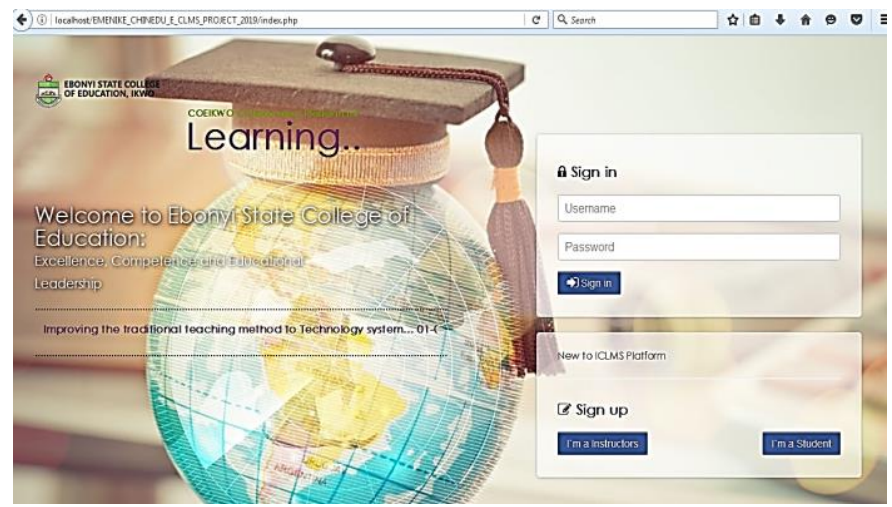

Fig. 5. The Instructor/Student Login Page.

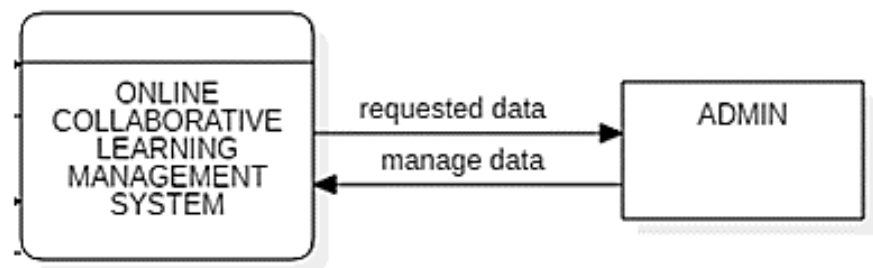

Fig. 6. Main Menu Design for Admin.

1) Subsystem design: The entire system consists of subsystems whose purpose is to help to achieve the aim of the system. The subsystems include:

a) Subsystem design: The entire system is made up of subsystems whose purpose is to help the system achieve its goal. The subsystems are as follows: a) The Admin Sub System, depicted in Fig. 7, is designed to allow administrators to manage students and instructors. 


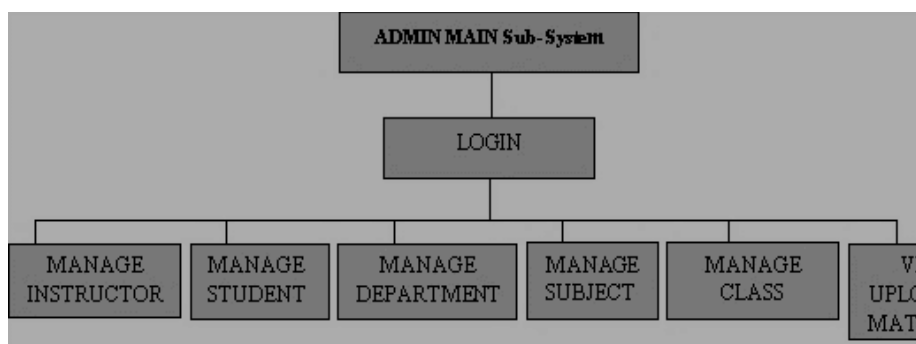

Fig. 7. The Admin Platform.

b) The Instructors/Teachers Subsystem, depicted in Fig. 8, is intended for instructors to perform a variety of tasks such as managing classes, scheduling classes, uploading materials, and uploading files.

c) The Student Subsystem, depicted in Fig. 9, is intended to allow students to interact with educational content.

2) Design of program modules: The new system is made up of several modules that work together to form the entire system. Here are a few examples:

- The admin subsystem consists of manage/view instructor module, manage/view student module, manage subject module, manage department module, view uploaded materials module.

- While the instructor and student subsystem consist of manage class module, schedule class module, upload material module, upload assignment module, upload course module, post comment module and view class module, submit assignment module, download material module, post comment module, respectively.

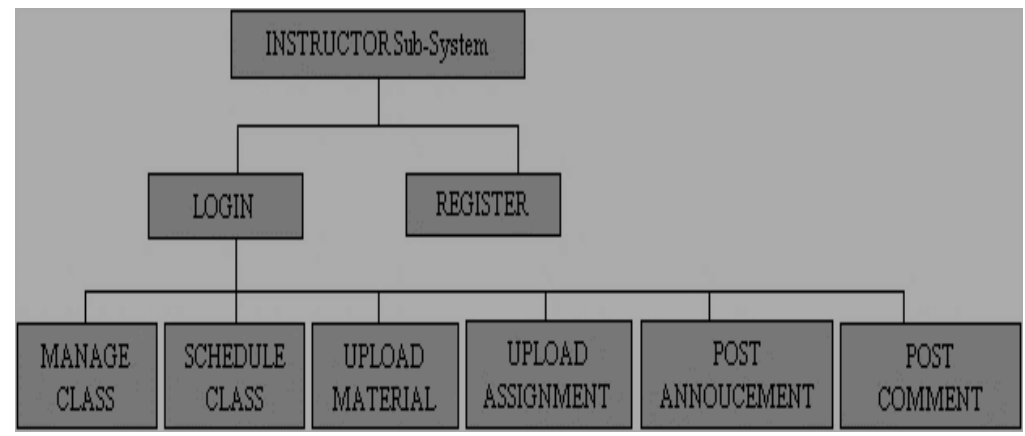

Fig. 8. The Instructor Sub System.

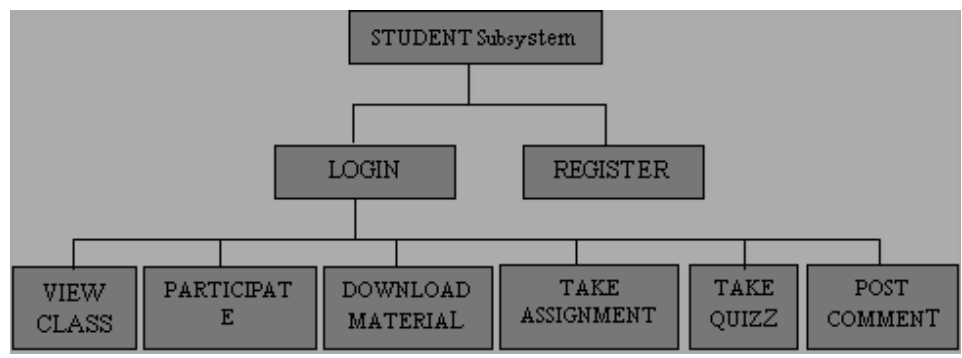

Fig. 9. The Student Platform.

3) Database development tools and structure: MYSQL, one of the most powerful powering tools for software that runs on the XAMPP server, was used in the development of this system. It has customizable views, query caching, crossplatform support, triggers, and built-in replication. A relational database management system (RDBMS), specifically MYSQL Server, is used to implement the database design. Tables I and II show some of the tables that were used. Table I depicts the student table, while Table II depicts the administrative table.

TABLE I. THE STUDENT TABLE

\begin{tabular}{|c|c|c|c|c|c|c|c|}
\hline \# & Name & Type & Collation & Attributes & Null & Default & Extra \\
\hline 1 & student_id - & $\operatorname{Int}(11)$ & & & NO & None & Auto_Increment \\
\hline 2 & firstname & $\operatorname{Varchar}(50)$ & & & NO & None & \\
\hline 3 & lastname & $\operatorname{Varchar}(50)$ & & & $\mathrm{NO}$ & None & \\
\hline 4 & Class_id & $\operatorname{Int}(11)$ & & & $\mathrm{NO}$ & None & \\
\hline 5 & username & $\operatorname{Varchar}(50)$ & & & NO & None & \\
\hline 6 & password & $\operatorname{Varchar}(50)$ & & & NO & None & \\
\hline 7 & location & $\operatorname{Varchar}(100)$ & & & NO & None & \\
\hline 8 & status & Varchar(100) & & & $\mathrm{NO}$ & None & \\
\hline
\end{tabular}

TABLE II. THE ADMIN TABLE

\begin{tabular}{|l|l|l|l|l|l|l|l|}
\hline$\#$ & Name & Type & Collation & Attributes & Null & Default & Extra \\
\hline 1 & user_id & Int(11) & & & NO & None & Auto_Increment \\
\hline 2 & username & Varchar(50) & & & NO & None \\
\hline 3 & password & Varchar(50) & & NO & None & \\
\hline 4 & firstname & Varchar(50) & & NO & None & \\
\hline 5 & lastname & Varchar(50) & & NO & None & \\
\hline
\end{tabular}




\section{B. Admin Menu Implementation}

This menu allows the CLMS administrator to manage instructors and students. It was designed to monitor all the activity progress of both students and instructors. Fig. 10 depicted the picture of the admin main menu showing its entire menu at the left side bar navigation. The center content is the information feature that presents activity progress of all activities of the instructor and student perform on their home pages. This Admin managed the instructors, set up the modules and could create/edit/delete users. The administrator has direct access to the database.

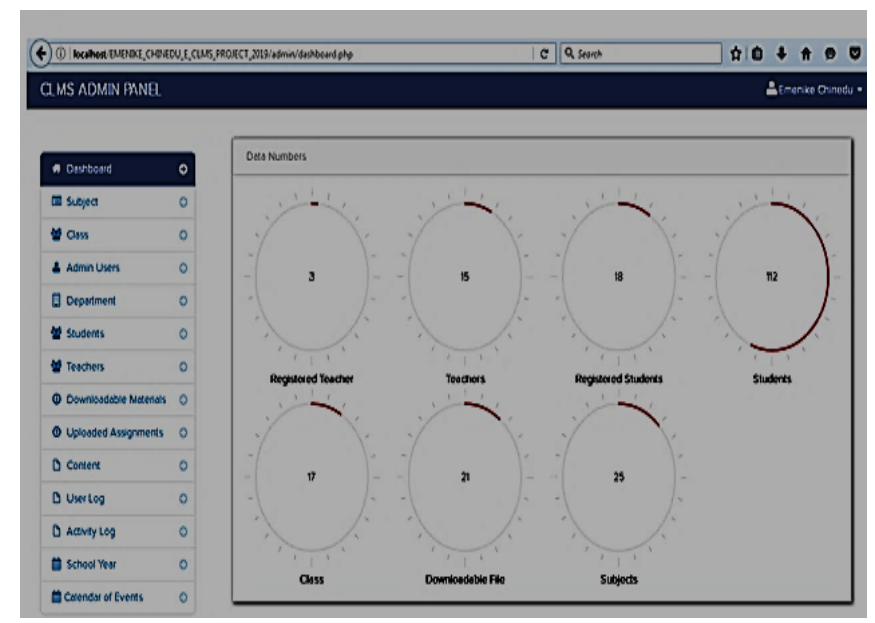

Fig. 10. The Admin View Implementation.

\section{Students Menu Implementation}

Students complete their profile on the system on first login. Fig. 11 shows the program Flowchart for Student Registration and Verification. Upon login, checks for notification of any task. They can also receive a text message on their phone via web service notifying them of any task. The user can also see his or her group members whenever a group task is given. The user can also respond to any task as appropriate by uploading files, posting answers on the joint collaborators widget and posting links for references in other for group member to read further and communicates to the instructors if need be.

\section{Subsystem Implementation}

1) Manage/view instructor and students module: The manage/view instructor and students' module are one of the modules that made up the admin subsystem. At this module, the admin must have sign in into the system to view this module. This module displays the list of all eligible students and teacher/instructor. Fig. 12 presents the add/view of student sub system module.

2) Manage/add department module: This module is made up of the instructor/lecturer subsystem. At this module, the instructor must be signed in before viewing the modules that were created in the department. Fig. 13 displays the add department module design.

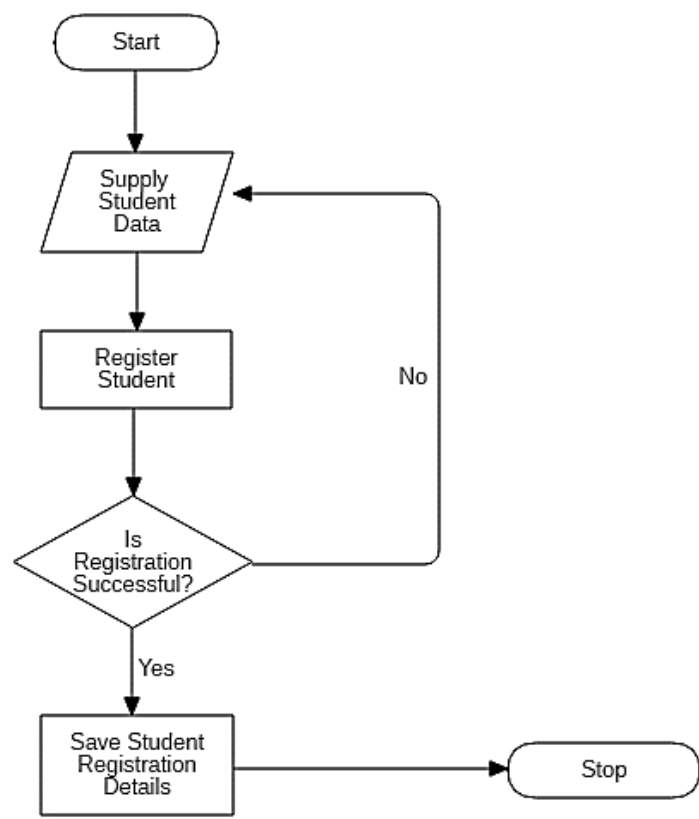

Fig. 11. Program Flowchart for Student Registration and Verification.

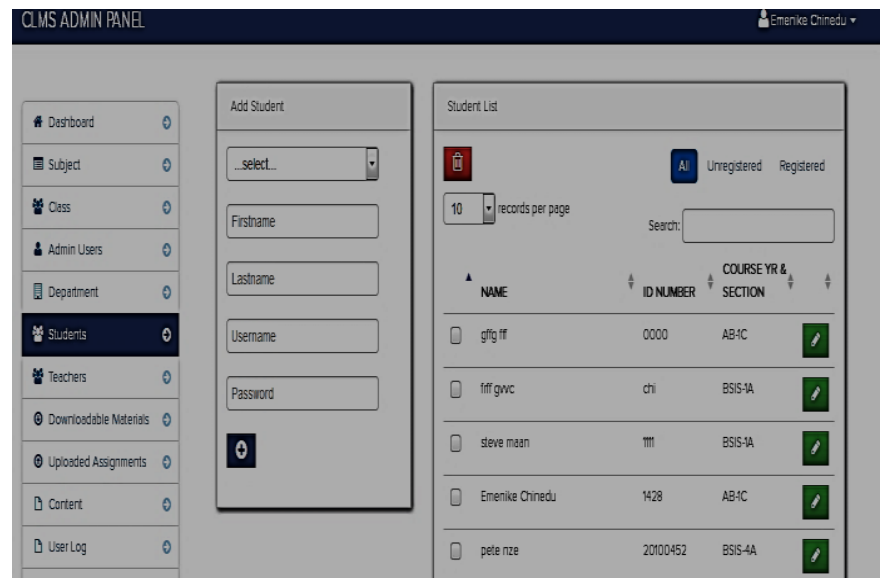

Fig. 12. Add/View of Student Sub System Module.

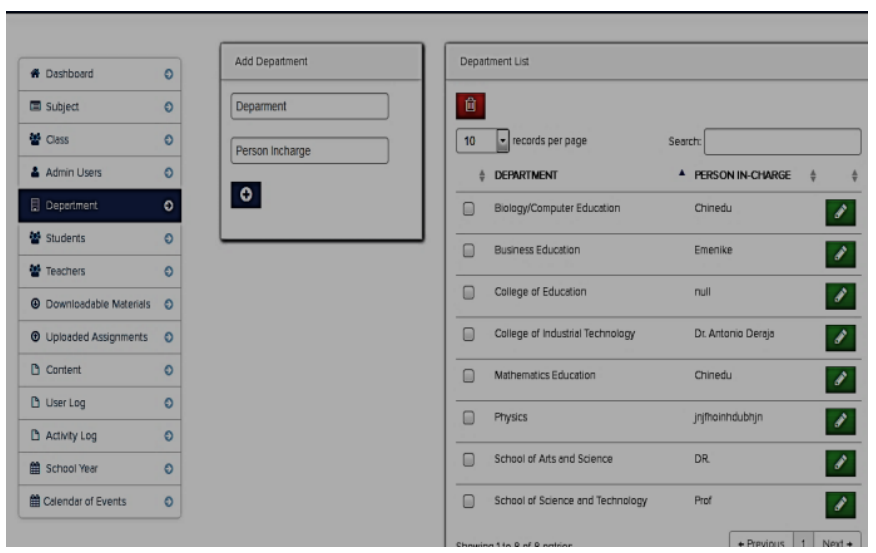

Fig. 13. Add Department Module Design. 


\section{3) Algorithm for the module of subsystem implementation:} In this section, we focused on the underground implementation of the scheduled class session in the instructors' and students' dashboards. Algorithms that implement these modules of systems in natural language are shown in Fig. 14 and Fig. 15, respectively.

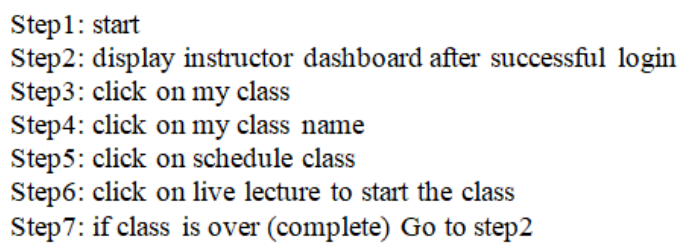

Fig. 14. The Algorithm for Schedule Class Session in the Dashboard of the Instructor.

\author{
Step1: start \\ Step2: display student dashboard after successful login \\ Go to Step 3 \\ Step3: click on my class \\ Step4: click on my class name \\ Step5: click on Participate in class \\ Step6: click on join to start the class \\ Step7: if class is over (Complete) Go to step2.
}

Fig. 15. The Algorithm for Class Session of the Students.

\section{TEST RESULTS}

These are the outcomes of the feasibility test for the tested system. They demonstrate a fully implemented system when tested with real-time data. The following testing and debugging methods were applied namely, Unit Testing, Integration Testing, and Alpha Testing.

Unit Testing: This test was carried out on every module of the system to verify proper functionality and ascertain if they were error free. Error found were noted down and corrected immediately.

Integration Testing: This test involves testing of how the various modules interact. This was done by combining the system modules to see how they interact and ensuring that their performance does not affect or obstruct the functionality of others.

Alpha Testing: Sample data were used to test the system's functionality to see if it would perform as expected and meet requirements without errors.

Fig. 16 shows a sample output for a message module for instructors' view.

\section{A. System Integration}

The system integration depicted in Fig. 17 shows how the various subsystems were combined to form the main system. The following elements were incorporated: a) The Student Subsystem b) The Instructor/Teacher Subsystem c) The Adm Subsystem.

\section{B. Choice of Programming Language}

In the development of the CLMS, PHP (PHP: Hypertext Pre-processor) was chosen as the server-side scripting language for the back-end development of the system. MYSQL was used for the database design. This is the database development language that served as the back end of the software for storing information because of its high maintenance and security. It was used in creating communication and connection between the application and the database. JavaScript was also used along with AJAX to make the web application interactive. It is a high-level interpreted language. JQUERY were also used for carrying out client-side manipulations. Other languages for the client side (front end development) such as HTML (Hyper Text Markup Language) used to lay out the web pages, CSS (Cascading Style Sheets) to describe hoe HTML elements are to be displayed on screen, and BOOTSRAP which consists of HTML CSS JavaScript framework used to make the design responsive on laying out the web pages.

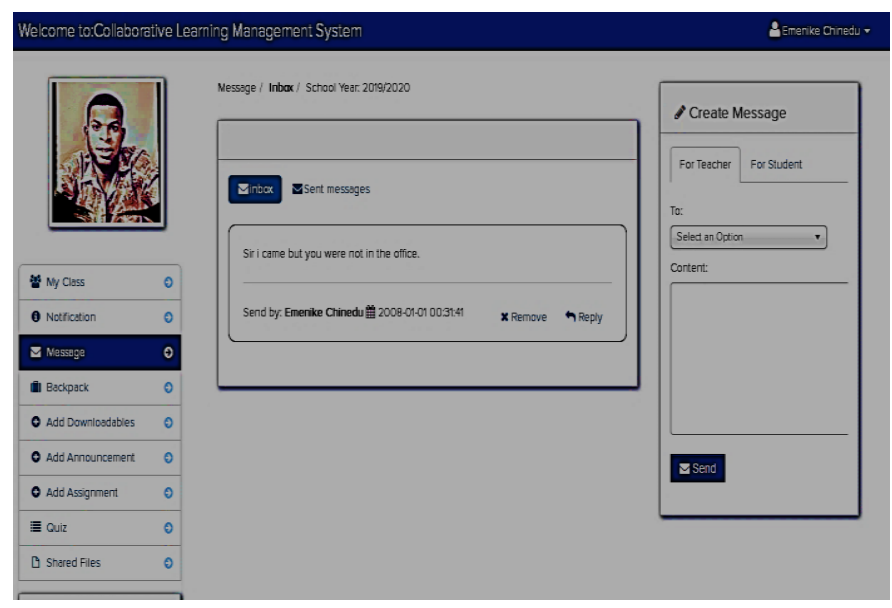

Fig. 16. Message Module Instructor View.

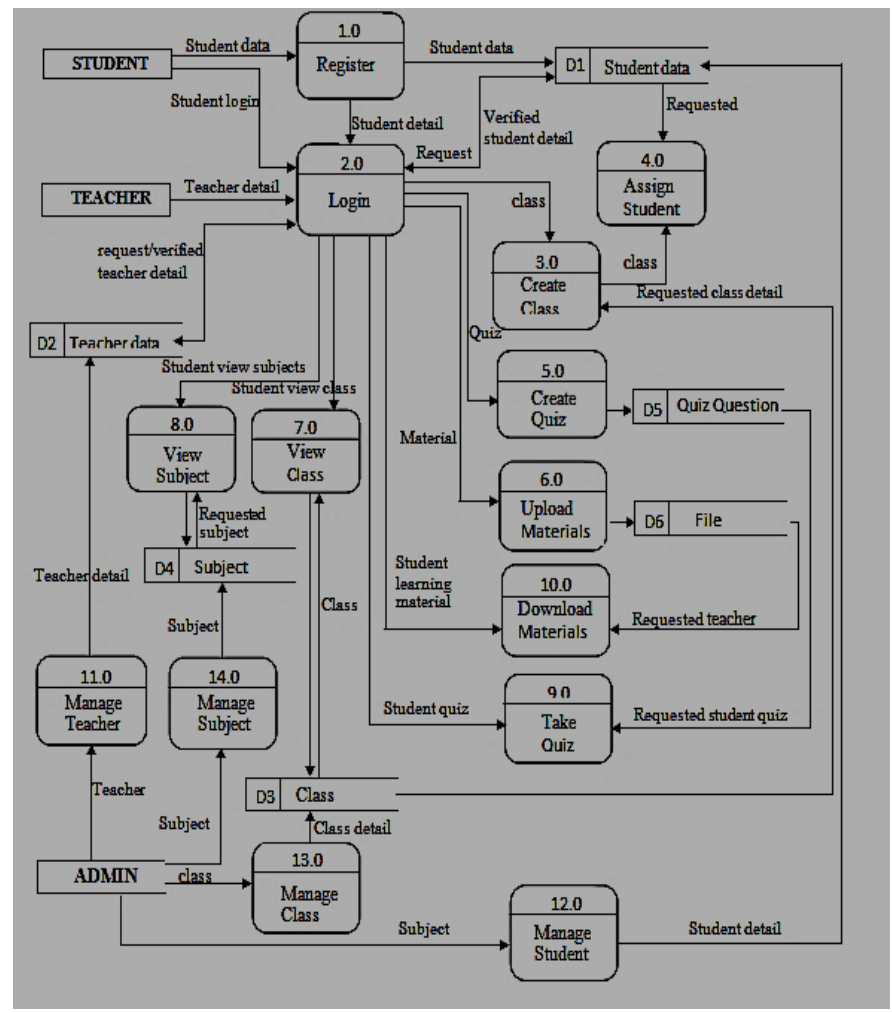

Fig. 17. An Integration of the System Subsystems. 


\section{CONCLUSION}

The challenges of conventional student teaching and learning in educational systems, as well as the abrupt disruption of our education system due to the COVID 19 pandemic, prompted this research. Despite the existence of strategies to compensate for the effects of discontinued face-toface teaching and learning as a result of the pandemic, such as the use of televisions and radios to compensate for the effects of discontinued face-to-face teaching and learning, such alternatives have not contributed to effective student learning. This paper suggests that these issues can be addressed by implementing a new collaborative management system centered on effective learning and employing an integrated approach. As a result, the following inputs were considered during this study:

1) The system that allows a collaborative learning through interactive tools that entails receiving feedback from instructors easy knowledge management, assessments, and quiz. Providing an interactive chats box between instructors and students and students to students and providing repository of course materials via e-portfolio that students can access.

2) Instructors' module which enable instructors to various tasks to be assigned to students, set deadline for task, track and monitor the progress of each student and generate report for assessment-based students' participations on the collaborative platform of the system.

3) Students Module that allow students to complete their profile on the system on first login, checks for notification of any task. Also, the students receive a text message on their phone via web service notifying them of any task. Update's students whenever a group task is given. Students respond to any task as appropriate by uploading files, posting answers on the joint collaborator's widget, and posting links for references for other group members to read and communicates back to instructor.

The future iteration of this study will involve understanding instructors and students' perceptions about their experience of using CLMS to ascertain whether the CLMS system impacted positively to teaching and learning, and whether the use of CLMS minimize numerous learning problems with the conventional classroom learning environment in Nigeria educational system. This is importance in order to know the impact and efficacy of the CLMS with users in an educational setting.

\section{REFERENCES}

[1] S. C. Eze, V.C. Chinedu-Eze, C.K. Okike, A.O. Bello. Factors influencing the use of e-learning facilities by students in a private Higher Education Institution (HEI) in a developing economy. Humanities and Social Sciences Communications. 2020 Oct 27;7(1):1-5.
[2] N. Hedge, L. Hayward . Redefining Roles: university e-learning contributing to lifelong learning in a networked world?. E-Learning and Digital Media. 2004 Mar;1(1):128-45.

[3] T. Ikwunne, S.O. kide, K.C. Oketa, N. E. Richard-Nnabu, U. Edward . "Mobile Platform for Study and Collaborative Knowledge Construction in Students Course Learning" International Journal of Computer and Organization Trends 11.3 (2021): 20-25. K. Elissa, "Title of paper if known," unpublished.

[4] Y.D. Usman. Educational Resources: An Integral Component for Effective School Administration in Nigeria. Online Submission. 2016;6(13):27-37.

[5] J. König, D.J. Jäger-Biela, N. Glutsch. Adapting to online teaching during COVID-19 school closure: teacher education and teacher competence effects among early career teachers in Germany. European Journal of Teacher Education. 2020 Aug 7;43(4):608-22.

[6] L. Darling-Hammond, L. Flook, C. Cook-Harvey, B. Barron, D. Osher . Implications for educational practice of the science of learning and development. Applied Developmental Science. 2020 Apr 2;24(2):97140.

[7] H. Meishar-Tal, G. Kurtz, E. Pieterse. Facebook groups as LMS: A case study. International Review of Research in Open and Distributed Learning. 2012;13(4):33-48.

[8] U.N Eze, M.M Sefotho, C.N Onyishi, C. Eseadi. Impact of COVID-19 pandemic on Education in Nigeria: Implications for Policy and Practice of e-learning. Library Philosophy and Practice. 2021:1-36.

[9] P.D. Sharmila. Networked Collaborative Learning. SCIENCE AND HUMANITIES. 2017 Jan:345.

[10] H. Jeong , C.E. Hmelo-Silver. Seven affordances of computer-supported collaborative learning: How to support collaborative learning? How can technologies help?. Educational Psychologist. 2016 Apr 2;51(2):247-65.

[11] B. Edmunds, M. Hartnett. Using a learning management system to personalise learning for primary school students. Journal of Open, Flexible and Distance Learning. 2014 Jan;18(1):11-29.

[12] Y. Xiong , HK Suen. Assessment approaches in massive open online courses: Possibilities, challenges and future directions. International Review of Education. 2018 Apr;64(2):241-63.

[13] H. Le, J. Janssen, T. Wubbels. Collaborative learning practices: teacher and student perceived obstacles to effective student collaboration. Cambridge Journal of Education. 2018 Jan 2;48(1):103-22.

[14] D. Barreto, A. Rottmann,, \& S. Rabidoux, (2020). Learning Management Systems. EdTech Books. https://edtechbooks.org/learning _management_systems.

[15] E. Van Laar, A.J. Van Deursen, J.A Van Dijk, J. De Haan . The relation between 21st-century skills and digital skills: A systematic literature review. Computers in human behavior. 2017 Jul 1;72:577-88.

[16] P.C. Oliveira , C.J Cunha , M.K Nakayama . Learning Management Systems (LMS) and e-learning management: an integrative review and research agenda. JISTEM-Journal of Information Systems and Technology Management. 2016 May;13:157-80.

[17] G. Roque, I. Chamovitz, J. Araujo, M. Gouvea, R. Cardoso, S. Azambuja, \& S. Moura. Relevant aspects for the development of educational environments for the web. In: Proccedings of CISCI, 3rd Iberoamerican Conference on Systems, Cybernetics and Informatics. Miami, United States. 2004.

[18] S. Mehall . Purposeful Interpersonal Interaction in Online Learning: What Is It and How Is It Measured?. Online Learning. 2020 Mar;24(1):182-204. 